Горловского института иностранных языков

Донбасского государственного педагогического университета (Бахмут, Донеикая область, Украина) allagabidullina54@gmail.com

\title{
ДИСКУРСИВНАЯ МЕТОНИМИЯ КАК СРЕДСТВО СОЗДАНИЯ КОЛОРИТА ЭПОХИ (НА МАТЕРИАЛЕ РОМАНА И. ИЛЬФА И Е. ПЕТРОВА «ДВЕНАДЦАТЬ СТУЛЬЕВ»)
}

\footnotetext{
Предметом исследования выступает дискурсивная метонимия как средство создания колорита эпохи. Цель статьи - показать, как с ее помощьюю в романе изображены реалии первых десятилетий Советской власти. «Двенадиать стульев»- это своеобразная «энииклопедия» советской жизни 20-х годов прошлого века, путеводитель под обложкой авантюрного романа. Метонимия, часто гротескная, позволяет подчеркнуть во внешности и характере героев наиболее яркую деталь, создать запоминающийся образ. Этот прием фокусирует внимание читателя на том или ином объекте, переводит его с заднего плана на передний (с периферии в цеентр) и наоборот. В результате явление четко выделяется из круга объектов действительности и становится выпуклым, ярким и выразительным, похожим на крупный план в кино.

Дискурсивная метонимия чаще всего появляется как следствие сокращения словосочетания в одной лексеме. Эллипсису подвергается его субстантивный элемент, который выступает в роли главного (опорного) слова. В основном «расшифровка» эллиптической метонимии рассчитана на фоновые знания адресата-читателя.

Еще одна разновидность дискурсивной метонимии - смещено определение как частный случай гипаллаги. Во время ее образования компонент, отделяясь от иелостной конструкиии, смещается к началу структуры высказывания, а остальное сокрашается. Это приводит к образованию субстантивно-адъективного словосочетания, которое функционирует как более обобщенный и кратко описанный. Чаме всего смещение определения выполняет функиию сжатого, обобщающего описания. Если же она находится в начале микротекста, то ее задача - ввести в дискурс информацию, которая требует толкования.

Нередко метонимия основывается на партонимических (синекдоха) и гипер-гипонимических отношениях. Гипер-гипонимичная метонимия является средством связи предложений в тексте и предотврашает тавтологии. Она может стать источником многочисленных эвфемизмов.

Проанализирована иллокутивная метонимия, которая создается за счет косвенных речевых актов.

Ключевые слова: дискурсивная метонимия, эллиптическая метонимия, иллокутивная метонимия, синекдоха, смещченное определение.
}

Алла ГАБІДУЛЛІНА, orcid.org/0000-0002-4271-4103 доктор філологічних наук, професор, професор кафедри мовознавства та російської мови

Горлівського інституту іноземних мов Донбаського державного педагогічного університету (Бахмут, Донеиька область, Украӥна) allagabidullina54@gmail.com

\section{ДИСКУРСИВНА МЕТОНІМІЯ ЯК ЗАСІБ СТВОРЕННЯ КОЛОРИТУ ЕПОХИ (НА МАТЕРІАЛІ РОМАНУ І. ІЛЬФА І Е. ПЕТРОВА «ДВАНАДЦЯТЬ СТІЛЬЦІВ»)}

\footnotetext{
Предметом дослідження постає дискурсивна метонімія як засіб створення колориту епохи. Мета статmi - показати, як за ї̈ допомогою в романі зображено реалії периих десятиліть Радянської влади. "Дванадияять стільиів»- ие своєрідна «енциклопедія» радянського життя 20-х років минулого століття, путівник під обкладинкою авантюрного роману. Метонімія, часто гротескна, дозволяє увиразнити в зовнішності й характері героїв найяскравішу деталь, створити образ, щзо запам'ятовується. Цей прийом фокусує увагу читача на тому чи іншому об'єкті, переводить його із заднього плану на передній (з периферії в ичентр) $і$ навпаки. У результаті явище чітко виділяється з кола об 'єктів дійсності й стає опуклим, яскравим і виразним, схожим на великий план у кіно.
} 
Дискурсивна метонімія найчастіше з'являється як наслідок скорочення словосполучення до однієї лексеми. Еліпсису піддається його субстантивний елемент, який виступає в ролі головного (опорного) слова. Здебільшого «розшифровка» еліптичної метонімї розрахована на фонові знання адресата-читача.

Ще один різновид дискурсивної метонімії- зміщене означення як окремий випадок гіпалаги. Під час ї̈ утворення компонент, відділяючись від ијілісної конструкиії, зміщується до початку структури висловлювання, а решта скорочується. Це приводить до утворення субстантивно-ад'єктивного словосполучення, яке функиіонує як узагальненіший і стисліший опис. Найчастіше зміщзене означення виконує функиію стисненого, узагальнювального опису. Якщо ж вона знаходиться на початку мікротексту, то ї̈ завдання - ввести в дискурс інформаиію, щзо потребує розтлумачення.

Нерідко метонімія трунтується на партонімічних (синекдоха) і гіпергіпонімічних відношеннях. Гіпергіпонімічна метонімія є засобом зв'язку речень у тексті й запобігає тавтологї. Вона може стати джерелом численних евфемізмів.

Проаналізовано ілокутивну метонімію, щуо створюється шляхом непрямих мовленнєвих актів.

Ключові слова: дискурсивна метонімія, еліптична метонімія, ілокутивна метонімія, синекдоха, зміщене означення.

\author{
Alla GABIDULLINA, \\ orcid.org/0000-0002-4271-4103, \\ Doctor of Philological Science, Professor, \\ Professor at the Department of Linguistics and Russian \\ Horlivka Institute for Foreign Languages \\ of the Donbas State Pedagogical University \\ (Bakhmut, Donetsk region, Ukraine) allagabidullina54@gmail.com
}

\title{
DISCURSIVE METONYMY AS A MEANS OF CREATING THE COLOURING OF THE ERA (ON THE MATERIAL OF THE NOVEL BY I. ILF AND Y. PETROV "THE TWELVE CHAIRS")
}

The subject of this research is discursive metonymy as a means of creating the coloring of the era. The purpose of the article is to show how, with its help, the novel describes the realities of the first decades of the Soviet government. "The Twelve Chairs" is a kind of "encyclopedia" of Soviet life in the 1920s, a guidebook under the cover of an adventure novel. Metonymy, often grotesque, makes it possible to highlight the most striking details in the appearance and personality of the characters, to make the image memorable. This technique focuses the reader's attention to a particular object, transfers it from background to foreground (from the periphery to the center) and vice versa. As a result, the phenomenon clearly stands out from the circle of objects of reality and becomes convex, bright and expressive, similar to a close-up in a movie.

Discursive metonymy most often appears as a result of the reduction of a phrase to one lexeme. Its substantive element, which acts as the main (supporting) word, is subjected to ellipsis. In most cases, the "decoding" of elliptic metonymy is based on the background knowledge of the addressee-reader.

Another kind of discursive metonymy is a displaced definition as a special case of the hippalagus. During its formation, the component, being separatied from the integral structure, shifts to the beginning of the structure of the statement, and the rest is reduced. This leads to the creation of a substantive-adjective phrase, which functions as a more generalized and concise description. Most often, a displaced definition serves as a concise, generalized description. If it stands at the beginning of the microtext, then its task is to introduce information into the discourse that requires clarification.

Often, metonymy is based on partonymic (synecdoche) and hyper-hyponymic relationships. Hyper-hyponymic metonymy serves as a means of connecting sentences in a text and prevents tautology. It can be the source of numerous euphemisms.

The illocutionary metonymy, created by indirect speech acts, has also been analyzed.

Key words: discursive metonymy, elliptic metonymy, illocutionary metonymy, synecdoche, displaced definition.

Постановка проблемы. Индивидуальноавторские метонимы, несмотря на распространенность этого тропа, проанализированы в научной литературе, на наш взгляд, недостаточно. В особой мере это относится к произведениям И. Ильфа и Е. Петрова, где такой стилистический прием наряду с другими является элементом идиостиля писателей. Лишь в одной статье (Тимофеева, 2016) мы нашли информацию о метонимии, участвующей в создании художественного образа в романе «Двенадцать стульев».

Анализ исследований. Метонимия давно является предметом изучения лингвистов. Особенно тщательно проанализирована лексикализованная метонимия, зафиксированная в словарях. Она исследована с точки зрения типов переноса значения, семантических сдвигов: частьцелое, частное-общее, причина-следствие, мате- 
риал-изделие, местность-люди и многое другое. С позиций когнитивного подхода метонимия - это процесс, при котором одна единица обеспечивает ментальный доступ к другой когнитивной единице в пределах фрейма (Kövecses, 2006), а метонимическое значение создается в результате свертывания фрейма до уровня слота (при этом название одного слота переносится на другой) (Кобозева, 2000; Меликян, 1998) В последние десятилетия метонимические переносы описаны не только на уровне слова, но и других единиц языковой системы: морфем, фразеологизмов, словосочетаний, предложений (Кубрякова, 2012; Гажева, 2014). К анализу подключают аппарат прагмалингвистики, в частности теорию речевых актов и дискурсологию.

Предметом нашего исследования является дискурсивная метонимия как средство создания колорита эпохи. Цель статьи - показать, как с ее помощью в романе «Двенадцать стульев» описаны реалии первых десятилетий Советской власти.

Изложение основного материала. Роман «Двенадцать стульев» - это своего рода «энциклопедия〉 советской жизни 20 годов прошлого века, путеводитель под обложкой авантюрного романа. Сюжет, связанный со странствиями главных героев по городам и весям, позволяет авторам делать панорамные зарисовки больших городов и небольших сел, рек и морей, гор и степей. Дается описание персонажей, играющих разные социальные роли. Эти и бывшие дворяне, тоскующие по старому режиму, и священники, и служащие разнообразных учреждений, и журналисты, актеры, музыканты, студенты и бедолаги из домов престарелых. Мы видим огромное количество деталей их быта. Метонимия, часто гротескная, позволяет выделить в облике и характере этих героев наиболее яркую деталь, сделать образ запоминающимся. Этот прием фокусирует внимание читателя на том или ином объекте, переводит его с заднего плана на передний (из периферии в центр) и наоборот (Падучева, 1999). В результате явление, описываемое автором, отчетливо выделяется из круга объектов действительности и становится выпуклым, ярким и выразительным, похожим, по О. В. Раевской (Раевская, 1999), на крупный план в кино.

Дискурсивная метонимия чаще всего появляется в результате сокращения словосочетания до одной лексемы. Эллипсису подвергается его субстантивный элемент, выступающий в роли главного (опорного) слова.

В большинстве случаев «расшифровка» эллиптической метонимии рассчитана на фоновые зна- ния адресата-читателя (они были у современников И. Ильфа и Е. Петрова, но сейчас многие метонимические переносы нуждаются в комментариях).

Журналисты газеты «Станок» пишут о секаровской жидкости: «- $У$ нас секаровская жсидксть! - кричали они грустными голосами. - Жидкость завтра. Сегодня публикуем наши приложения». Речь идет о средстве омоложения на основе вытяжки из семенных желёз животных, созданном французским физиологом Ш. Броун-Секаром.

Бесталанных музыкантов Галкина, Палкина, Малкина, Чалкина и Залкинда в театре Колумба называют «могучей кучкой» (ироническая аллюзия на творческое содружество знаменитых композиторов, или Балакиревский кружок). В дальнейшем словосочетание редуцируется в метоним «кучка»: «- Так, так, - говорила кучка с иронией, - а мы должны будем репетировать, сидя на койках...».

В театр Колумба пытаются пройти по контрамарке многочисленные сотрудники разных организаций, далеких от искусства, в том числе «Фортинбрас при Умслопогасе». Это название в узком контексте обыгрывается дважды, и онимы превращаются в апеллятивы. В первом случае Остап, пробиваясь к администратору, расталкивает фортинбрасовцев, во втором - тот же театральный чиновник жалуется на жизнь очередному умслопогасу. Оба наименования лица получают в тексте значение «дармоед, халявщик» (антономасия, прономинация). Здесь пародируются неудобоваримые советские аббревиатуры, соединившие имена двух литературных героев: норвежского принца из трагедии У. Шекспира «Гамлет» и зулусского воина из романа Р. Г. Хаггарда «Аллен Квотермейн».

В редакции газеты «Станок», куда попадают стулья, служат аяксы из отдела писем. В этой номинации тоже заключается немалая ирония: близкие по духу Аяксы из «Одиссеи» Гомера - это необузданные и гордые герои, выступающие против воли богов и людей, а в романе «Двенадцать стульев» - мелкие служащие, которых никто не замечает, а о родстве душ и говорить не приходится.

Грузчики на вокзале названы Ермаками Тимофеевичами с никелированными бляхами на сердце. На лубочных картинках знаменитый предводитель казачьих отрядов, завоевавших Сибирь, изображается как могучий длиннобородый воин в кольчуге с «зерцалом» - блестящей пластиной. Та же деталь одежды с личным номером и названием станции имеется и на униформе носильщиков. Кстати, лексема сердие тоже результат эллип- 
тического метонимического переноса: «бляхи на одежде, расположенные на уровне сердца».

Эллиптическая метонимия может заменять целую ситуацию. Вспомним собрание подпольной организации «Меча и орала» (основанной предприимчивым Бендером), на котором его участники распределяют между собой должности, упраздненные Советской властью. Они прекрасно осознают и мифичность тайного союза, и опасность пребывания в нем, но как хочется вернуть прошлое!!! «- Что же mbl, дурак, кричишь? спросил губернатор. - Хочешь в милиции ночевать? - Мне нельзя в милиции ночевать, - ответил городской голова, - я советский служащий $<\ldots>$ »). Страх перед разоблачением вынуждает их идти в НКВД, предавая не только свои мечты и надежды, но и соратников: «-Иду сознаваться, ответил Кислярский. - В чем? - В мече и орале».

Еще одна разновидность дискурсивной метонимии, широко представленная в романе, - смещенное определение как частный случай гиппалаги. К. Я. Сигал называет ее дислокационно-компрессивной (дальше - ДКМ): беспатентные лотошники, объявления с распльвшимися химическими буквами, школьники первой ступени, моторы харьковская работа; иветная очередь («очередь из людей в цветных одеждах»), кисейные окна, мадам Грицацуева - бриллиантовая вдовушка («владелица стула с бриллиантами») и прочее. При образовании ДКМ компонент, отделяясь от целостной конструкции, смещается к началу структуры высказывания, а то, что осталось от конструкции, сокращается. Как правило, такое перемещение приводит к созданию субстантивноадъективного словосочетания (Сигал, 2017), которое функционирует как более обобщенное и сжатое описание. Обычно в контексте смещенному определению предшествуют развернутые синтаксические структуры.

С помощью метонимии писатели высмеивают низкопробные постановки многочисленных экспериментальных театров: в театре «Колумб» музыканты играют на чем угодно - «бутылках, кружсках Эсмарха, саксофонах и больших полковых барабанах. Бутылочные стоны вызвали на сиену Подколесина». Эту «могучую кучку» как только в романе ни называют: «клистирной шайкой», «сифончатыми молодыми людьми». Последняя обсценная шутка построена на игре слов: «сифон», с одной стороны, название насоса, с другой - в 20-е годы жаргонное именование сифилиса.

Стулья, за которыми охотятся Бендер и Киса Воробьянинов, определяются в романе как превосходные, гамбсовские («изготовленные Г. Гамб- сом»). А тот, что находится в комнате шахматного кружка, имеет «самый обычный «гамбсовский вид». Мебель названа так по имени искусных немецких мастеров-мебельщиков Гамбсов, работавших в России, начиная с конца 18 века. Гарнитур в романе - не просто изысканная мебель, а символ прежней жизни, противопоставленной скудному существованию современников И. Ильфа и Е. Петрова в комнатах, напоминающих пеналы, где вместо кроватей - «матрацы на кирпичиках»: «Как сладко спать под демократический звон его пружин!».

Борзописец, работающий под псевдонимом «Принц Датский», в дальнейшем иронически именуется венценосным журналистом. Хунтов «скромно» позиционирует себя как человек, звучащий «в унисон с эпохой». В дальнейшем И. Ильф и Е. Петров называют его эпохальным мужчиной. Режиссера в кожаном армяке писатели именуют кожаным режиссером. Редактор странного журнала «Гигроскопический вестник» в дальнейшем определяется как гигроскопическая персона.

Скупой Ипполит Матвеевич вынужден отдать Бендеру свою долю в тридцать рублей за сведения о пропавшем стуле, но это его не огорчает, потому что «тридцатирублевая пылинка исчезала в сиянии бриллиантовой горы»», то есть бриллиантов, спрятанных в стуле.

Один из персонажей романа, архивариус Варфоломей Коробейников, страхует бабушку ста двух лет на тысячу рублей в надежде на ее скорую смерть, но та умирать не хочет и ведет себя достаточно активно. Внук везет ее на площадь послушать музыкальное радио («радио, транслирующее музыку»), надеясь, что «музыкальный рейс доконает старуху», но та отделывается легким недомоганием. «Тысячерублевый миражс таял, сроки истекали, надо было возобновлять страхование».

При образовании такого типа дискурсивной метонимии развернутые сложные словосочетания, полупредикативные конструкции, придаточные предложения и даже микротексты редуцируются до простого адъективного сочетания слов.

Завершающая речевой фрагмент дислокационно-компрессивная метонимия (см. выше) чаще всего выполняет функцию сжатого, обобщающего описания. Если же она находится в начале микротекста, то ее функция - введение в дискурс информации, требующей разъяснения. Так, эпизод, рассказывающий о поездке отца Федора, начинается так: Посадка в бесплацкартный поезд носила обычный кровопролитный характер. Затем в ССЦ описываются люди, которые мечутся по вагону, занимая свободные места, растерянность 
священника, не привыкшего к подобной суете, и прочее. В те времена билеты на подобные поезда указывали лишь номера вагона, поэтому места занимались в зависимости от ловкости и предприимчивости пассажиров, чем и объясняется «кровопролитный характер» посадки.

Синекдоха как разновидность дискурсивной метонимии представлена в романе не так часто, как предыдущие разновидности, но наряду с ними она является ярким средством создания иронического эффекта. Так, рассказывая о бедственном положении обитателей дома престарелых, авторы подчеркивают постоянное чувство голода. Одна из старушек сидит напротив плаката с изображением коровы, которая неизменно вызывает у нее «слюнотечение и перебои сердия. Во 2-м доме Собеса мясо к обеду подавали редко»: парнокопытное ассоциируется у обитательницы приюта не с домашним животным, а с мясом. Частотной является синекдоха «человек $\rightarrow$ его часть» (правда, она в большей степени лексикализованная, чем дискурсивная): действующее лицо, должностное лиио, городской голова и подобное. Перенос на уровне дискурса используется авторами для характеристики профессиональной принадлежности персонажей, например, музыкантов («человек $\rightarrow$ его голос») : «<... баритон $c$ негодованием заметил, что Ипполит Матвеевич живет с его женой, колоратурным сопрано». Тот же самый механизм семантического сдвига наблюдается в изображении людей как музыкальных инструментов (модель «инструмент - музыкант, играющий на нем»): «-Клистирная шайка! - сказал кларнет, поравнявшись с могучей пятеркой». $\mathrm{C}$ помощью синекдохи здесь указана не только профессиональная деятельность человека, но и дана его оценка, выделена важная для раскрытия образа черта характера. С использованием количественной метонимии может быть указана национальность человека или его место жительства (модель «единственное число вместо множественного»): «С Курского попадает в Москву кавказеи в коричневой бараньей шапке с вентиляиионными дырочками и рослый волгарь в пеньковой бороде». Реже применяется модель «множественное число вместо единственного»: «<...> гусар помел 6 монахи, чтобы постичь жизнь».

Гипер-гипонимическая метонимия является средством связи предложений в тексте и предупреждает тавтологию: «B коридоре шла ожесточенная борьба с огнетушителем. Наконеч человеческий гений победил, и пеногон, pacтоптанный железными ногами Паши Эмильевича, последний раз выблевал вялую струю и затих навсегда». У талантливых писателей эта функция не может быть единственной. В следующем эпизоде видовое наименование произведения живописи входит в речевой акт деклинатива - отказа от дорогостоящего, по мнению Бендера, номера в гостинице: $B$ трехрублевых номерах было все хорошо, за исключением картин. - Я не могу жить в одной комнате с пейзажами, - сказал Ocman. Получается, что поводом для смены номера служит не предмет интерьера как таковой, а жанр изобразительного искусства, и это придает всему высказыванию иронический характер. Благодаря родовидовой метонимии мы узнаем о том, что денежными знаками именовались банковые билеты, выпускавшиеся с 1922 года Госбанком СССР. Наименьшая из них по стоимости приравнивалась к довоенной десятирублевой золотой монете - червонцу, благодаря чему они и получили название «червонные банкнотыл».

Родовидовая метонимия может выступать в роли эвфемизма. В диалоге с Ипполитом Матвеевичем на московском вокзале Безенчук (похоронных дел мастер) упоминает товар, который он привез в столицу. Воробьянинов замечает рядом с ним шесть гробов. К числу табуированных наименований принято относить клопов, тараканов, мух и прочих зловредных насекомых. Приведем диалог Бендера с дежурным по этажу в гостинице: - Стиль каменного века, - заметил Остап с одобрением, - а доисторические жсивотные 8 матрацах у вас не водятся? Лукавый коридорный отвечает, что перед съездом или конференцией в номерах чисто, а в остальное время... всё может быть (это тоже примета советского времени - гостиницы с клопами и тараканами).

Разновидностью дискурсивной метонимии в романе является замена референтов внутри одного онима (антономасия). Вспомним эпизод, в котором Бендер и Воробьянинов вынужденно путешествуют по Кавказу. На величественных скалах они замечают уродливые надписи: «Коля и Мика, июль 1914 г». Остап предлагает «изувековечить» и себя: «Киса и Ося здесь были...». Мы видим аллюзию на опубликованное летом 1926 года стихотворение Маяковского «Канцелярские привычки». Фоновые знания читателя придают именам «Киса и Ося» неожиданный смысл: «Кисой Маяковский публично называл Л. Ю. Брик, а Осей - ее мужа, О. М. Брика, причем в июле 1927 года «Киса и Ося» действительно были на Кавказе» (Википедия). Еще один метонимический оним - Агафья Тихоновна. Так именуется актриса театра «Колумб», играющая роль главной героини в пьесе Н. В. Гоголя «Женитьба»: 
«3а соседним столиком сидела Агафья Тихоновна-молоденькая девушка с ногами твердыми и блестящими, как кегли».

Еще одна разновидность дискурсивной метонимии - иллокутивная, при которой одна из характеристик речевого акта может замещать сам речевой акт (дальше - РА). Речь идет о ситуативно-косвенных РА (по Д. Серлю), где соединяются две (а то и несколько) иллокутивные силы: первичная (имплицитная) и вторичная (эксплицитная). Интенция говорящего в таких высказываниях скрыта «под маской» другого речевого акта. Косвенные РА являются средством иронической характеристики персонажей. Так, о Кисе Воробьянинове авторы говорят, что он каждое утро приветствует себя на немецком и французском языках (тоже примета времени: бывшие дворяне пытаются хоть как-то сохранить свой статус-кво), но это не единственная иллокуция: «Сказанное при пробуждении «гут морген» обычно значило, что печень почаливает, что 52 года-не шутка и что погода нынче сырая». В дальнейшем измученный поисками сокровищ
Ипполит Матвеевич уже не поет «своих бонжуров и гутморгенов <...>». Иллокутивная сила нередко «озвучивается» авторами романа: «Он уводил ее в конеи коридора и у окна, между месткомом и женской уборной, говорил слова любви, на которые девушка отвечала: - У меня сегодня сверхурочная работа, и я очень занята. Это значило, что она любит другого». Интенция отказа выражена с помощью РА констатива.

Выводы. Изучение дискурсивной метонимии в романе «Двенадцать стульев» показало, что она играет значимую роль в создании иронического «портрета» советской страны 20 годов прошлого века. Этот троп создается за счет эллипсиса, смещенного определения как частного случая гиппалаги, партонимических и гипер-гипонимических отношений между словами, антономасии, косвенных РА. В произведениях И. Ильфа и Е. Петрова метонимия занимает значительное место, являясь стилеобразующим фактором, однако до сих пор она должным образом не описана, что и определяет перспективы дальнейшего исследования.

\section{СПИСОК ИСПОЛЬЗОВАННЫХ ИСТОЧНИКОВ}

1. Двенадцать стульев. Википедия : свободная энциклопедия. URL: https://ru.wikipedia.org/wiki/\%D0\%94\%D0\%B2 \%D0\%B5\%D0\%BD $\%$ D0\%B0\%D0\%B4\%D1\%86\%D0\%B0\%D1\%82\%D1\%8C_\%D1\%81\%D1\%82\%D1\%83\%D0\%BB\% $\mathrm{D} 1 \% 8 \mathrm{C} \% \mathrm{D} 0 \% \mathrm{~B} 5 \% \mathrm{D} 0 \% \mathrm{~B} 2$

2. Кобозева И. М. Лингвистическая семантика : учебное пособие. Москва : Эдиториал УРсс, 2000. 352 с.

3. Гажева И. Д. Аспекты и методы изучения метонимии в современной лингвистике. Мова. 2014. № 21. С. 150-153.

4. Кубрякова Е. С. В поисках сущности языка: Когнитивные исследования. Москва : Знак, 2012. 208 с.

5. Меликян А. А. Концептуальные модели семантики фразеологических единиц в свете идей когнитивизма (на материале фразеологических единиц библейского происхождения). Некоторые проблемы синхронного и диахронного описания языков : межвузовский сборник научных трудов. Пятигорск, 1998. С. 151-157.

6. Раевская О. В. О некоторых типах дискурсивной метонимии. Изв. РАН. Сер. лит. и яз. Т. 58. № 2. 1999. С. 3-12.

7. Падучева Е. В. Лексика поэзии и поэзия лексики. Роман Якобсон. Тексты, документы, исследования. Москва : РГГУ, 1999. С. 552-568.

8. Сигал К. Я. Дислокационно-субстантивная метонимия (на материале субстантивно-адъективных словосочетаний). Вопросы психолингвистики. 2017. URL: https://cyberleninka.ru/article/n/dislokatsionno-kompressivnayametonimiya-na-materiale-substantivno-adektivnyh-slovosochetaniy. C. 110-123.

9. Тимофеева Т. П. Метонимическая номинация человека в романе И. Ильфа и Е. Петрова «Двенадцать стульев». Современная наука: актуальные проблемы теории и практики. Серия «Гуманитарные науки». 2016. URL: http://www.vipstd.ru/index.php/\%D1\%81\%D0\%B5\%D1\%80\%D0\%B8\%D1\%8F-\%D0\%B3\%D1\%83\%D0\%BC\%D0\%B0 $\% \mathrm{D} 0 \% \mathrm{BD} \% \mathrm{D} 0 \% \mathrm{~B} 8 \% \mathrm{D} 1 \% 82 \% \mathrm{D} 0 \% \mathrm{~B} 0 \% \mathrm{D} 1 \% 80 \% \mathrm{D} 0 \% \mathrm{BD} \% \mathrm{D} 1 \% 8 \mathrm{~B} \% \mathrm{D} 0 \% \mathrm{~B} 5-\% \mathrm{D} 0 \% \mathrm{BD} \% \mathrm{D} 0 \% \mathrm{~B} 0 \% \mathrm{D} 1 \% 83 \% \mathrm{D} 0 \% \mathrm{BA}$ \%D0\%B8-2016/\%D0\%B3\%D1\%83\%D0\%BC\%D0\%B0\%D0\%BD\%D0\%B8\%D1\%82\%D0\%B0\%D1\%80\%D0\%BD\%D1 \%8B\%D0\%B5-\%D0\%BD\%D0\%B0\%D1\%83\%D0\%BA\%D0\%B8-2016-\%D0\%BD\%D0\%BE\%D1\%8F\%D0\%B1\%D1\%8 $0 \% \mathrm{D} 1 \% 8 \mathrm{C} / 1024-\mathrm{hum}-32$.

10. Kövecses Z. Language, Mind and Culture: A Practical Introduction. Oxford : Oxford University Press, 2006. 416 p.

\section{REFERENCES}

1. Dvenadcat' stul'ev. Vikipediya [Wikipedia]. URL: https://ru.wikipedia.org/wiki/\%D0\%94\%D0\%B2\%D0\%B5\%D0\%

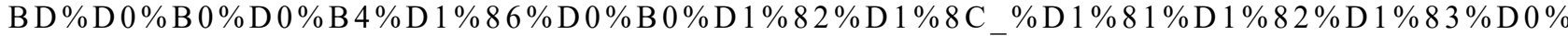
$\mathrm{BB} \% \mathrm{D} 1 \% 8 \mathrm{C} \% \mathrm{D} 0 \% \mathrm{~B} 5 \% \mathrm{D} 0 \% \mathrm{~B} 2$ [in Russian].

2. Kobozeva I. M. Lingvisticheskaya semantika [Linguistic Semantics]: uch. posobie. M. : Editorial URss, 2000. 352 c. [in Russian].

3. Gazheva I. D. Aspekty i metody izucheniya metonimii v sovremennoj lingvistike [Aspects and Methods of Studying Metonymy in Modern Linguistics]. Mova. 2014. № 21. S. 150-153 [in Russian].

4. Kubryakova E. S. V poiskah sushchnosti yazyka: Kognitivnye issledovaniya [In Search of the Essence of Language]. M. : Znak, 2012. 208 s. [in Russian].

5. Melikyan A. A. Konceptual'nye modeli semantiki frazeologicheskih edinic v svete idej kognitivizma (na materiale frazeologicheskih edinic biblejskogo proiskhozhdeniya). Nekotorye problemy sinhronnogo i diahronnogo opisaniya yazykov 
[Conceptual Models of the Semantics of Phraseological Units in the Light of the Ideas of Cognitivism (Based on Phraseological Units of Biblical Origin)] : mezhvuz. sb. nauch. trudov. Pyatigorsk, 1998. C. 151-157 [in Russian].

6. Raevskaya O. V. O nekotoryh tipah diskursivnoj metonimii [On Some Types of Discursive Metonymy]. Izv. RAN. Ser. lit. i yaz. T. 58. № 2. 1999. S. 3-12 [in Russian].

7. Paducheva E. V. Leksika poezii i poeziya leksiki [Vocabulary of Poetry and Poetry of Vocabulary]. Roman Yakobson. Teksty, dokumenty, issledovaniya. M. : RGGU, 1999. S. 552-568 [in Russian].

8. Sigal K. Y. Dislokacionno-substantivnaya metonimiya (na materiale substantivno-ad"ektivnyh slovosochetanij) [Dislocative and Compressive Metonymy (on the Material of Substantive-Adjectival Word-Combinations)]. Voprosy psiholingvistiki. 2017. URL: https://cyberleninka.ru/article/n/dislokatsionno-kompressivnaya-metonimiya-na-materiale-substantivno-adektivnyh-slovosochetaniy. S. 110-123 [in Russian].

9. Timofeeva T. P. Metonimicheskaya nominaciya cheloveka v romane I. Il'fa i E. Petrova "Dvenadcat' stul'ev" [Metonymic Nomination of a Person in I. Ilf and Ye. Petrov's Novel "The Twelve Chairs"]. Sovremennaya nauka: aktual'nye problemy teorii i praktiki. Seriya "Gumanitarnye nauki”. 2016 URL: http://www.vipstd.ru/index.php [in Russian].

10. Kövecses Z. Language, Mind and Culture: A Practical Introduction. Oxford : Oxford University Press, 2006.416 p. [in English]. 